\title{
Property Management System Based on.NET
}

\author{
Junli Xu \\ College of Information Engineering, Jiangxi University of Technology, Jiangxi Nanchang
}

Keywords: Property management; The.NET; Data storage; Information query

\begin{abstract}
. in order to use the advanced management to improve the level of property management, this paper designed and developed property management system based on.NET, as well as analysis of permissions, functional and performance requirements of this system. Set up tables and diagrams through analyzing the needs of the database and realize this final system. The system adopts the man-machine conversational mode, beautiful and friendly interface, flexible and convenient information query, safe and reliable data storage, and has maximized the implementation of easy installation, maintenance and operability.
\end{abstract}

\section{Introduction}

With the rapid development of market economy in our country and the improving of people's life, the simple community service already can't satisfy people's needs. How to use the advanced management means to improve the level of property management is an important task for the society. Faced with the challenge of the information age, it is no doubt that improves the property management by using of computer network management system is an effective way.

As a new industry, property management gradually becomes a booming industry which is closely related to people's daily life and the society. Currently the property management is in the key stage of growing up. For the whole property management industry, the only simple one-way manual management already can not adapt to raising demand of the property management. Network of computer is the approach to integrated management for property companies. As a part of computer application, using computer to manage the information of the community has the incomparable advantages comparing with the manual management. This property management system is software raised under the background of current situation, which is the key motive power for the enterprise to reduce the management cost, and improve work efficiency.

The poperty management system is an inevitable outcome of the combination of scientific management and information technology. Its advantages are as follows:

(1) A comprehensive automatic information management may grasp the situation of the community at any time.

(2) The system adopts the man-machine conversational mode, beautiful and friendly interface, flexible and convenient information query, safe and reliable data storage.

(3) Comprehensive query and improve work efficiency.

(4) Improve management and service level with the completed engineering archives management.

(5) Strong background monitoring function. 
(6) The system will inspect inputted data by strict examination, and eliminate human error as much as possible.

(7) This system has maximized the implementation of easy installation, maintenance and operability.

\section{Needs analysis}

Permission analysis of the system. According to the business and functional requirements, the whole system is divided into four permissions by department responsibility: property management permission, charge management permission, the basic setting permissions and system maintenance permission, in which each of the permission aims at corresponding function module in its duty. Specific permissions can not cover the entire system is as follows:

1) Property management permission: resident complaints, maintenance management, parking lots management, equipment maintenance management, etc.

(2) Charge management permission: charge registration, detailed query, summation query;

(3) The basic setting permissions: household materials, equipment materials, building materials, maintenance materials and parking data materials management.

(4) System maintenance permission: backup and restore of the system

According to different business and permissions, owners only have complaints and viewing permissions, so the system only set up an administrator login module.

Function analysis of the system. According to business requirements of the property management, the system should have the following functions:

(1) Due to operator's limited computer knowledge, a profound man-machine interface is needed.

(2) If the system has many users, a profound permission management is required.

(3) The convenient data query, which supports multiple conditions querying.

(4) To complain the owner through the network as well as repair service.

(5) The owners quickly and timely get the information of property management center's announcement and overdue bills of water, electricity and gas.

(6) Intelligent management of parking lots.

(7) Encountering the external environment (power, network virus) interference for the system, the system can automatically protect the safety of the raw data.

(8) The system data management is convenient, simple, and of strong stability.

(9) Property management center audit owners and feedback information timely and effectively.

According to business requirements, the final design of property management system includes five main function modules, which are property management, property management information, announcement management, basic settings and system maintenance modules. The specific plan is as follows:

(1) Property management module

The module is mainly responsible for owner's complaint management, owners repair service management, equipment maintenance management and management of parking lots.

(2) Property information management module 
The module is mainly responsible for complaints information, owners' repair information, equipment repair audition and Ross.

(3) The announcement management module

The module is mainly responsible for property management personnel, overdue bills, property announcement.

(4) The basic setup module

The module is mainly responsible for adding and editing owners' information as well as adding and editing parking information.

(5) System maintenance module

The module is mainly responsible for users' system settings, data backup and recovery.

\section{System design}

Introduction design. Property management is one of the most work branches showing humanity in the real estate industry. Nowadays, many real estate companies have set up property companies and realize the standardization and responsibility system of the property management, for example, Zhonghai Shenlan Property Company which is owned by China Real Estate is the most famous one in property management companies.

Through the business research of Zhonghai Shenlan Property Company, I first established the main design lines of this system. First of all, due to the limited computer knowledge of the operator, the system must own a man-machine interface. Secondly, because of the large amount of users, a better permission management is required. In addition, a convenient data query, multiple conditions supporting system is needed. For the convenience of the owners, functions of online complaint and maintenance should be configured. Intelligent management of parking and other basic information of owners are realized, including fee management of water, electricity and gas. And because this system is a long-term applied system, it can automatically protect the safety of the raw data when encounters the external interference (power cut, network virus). To sum up, this system peruses an orderly, efficient and perfect residential property management system.

System function design

This system belongs to the small and medium-sized network management system, can be effective applied in small and medium-sized property companies. Through the preliminary requirements analysis, determined design is centered on property management, property information management, announcement management, basic settings, system maintenance and other module design. The specific function of foreground is shown in Fig. 1, and the background is shown in Fig. 2: 


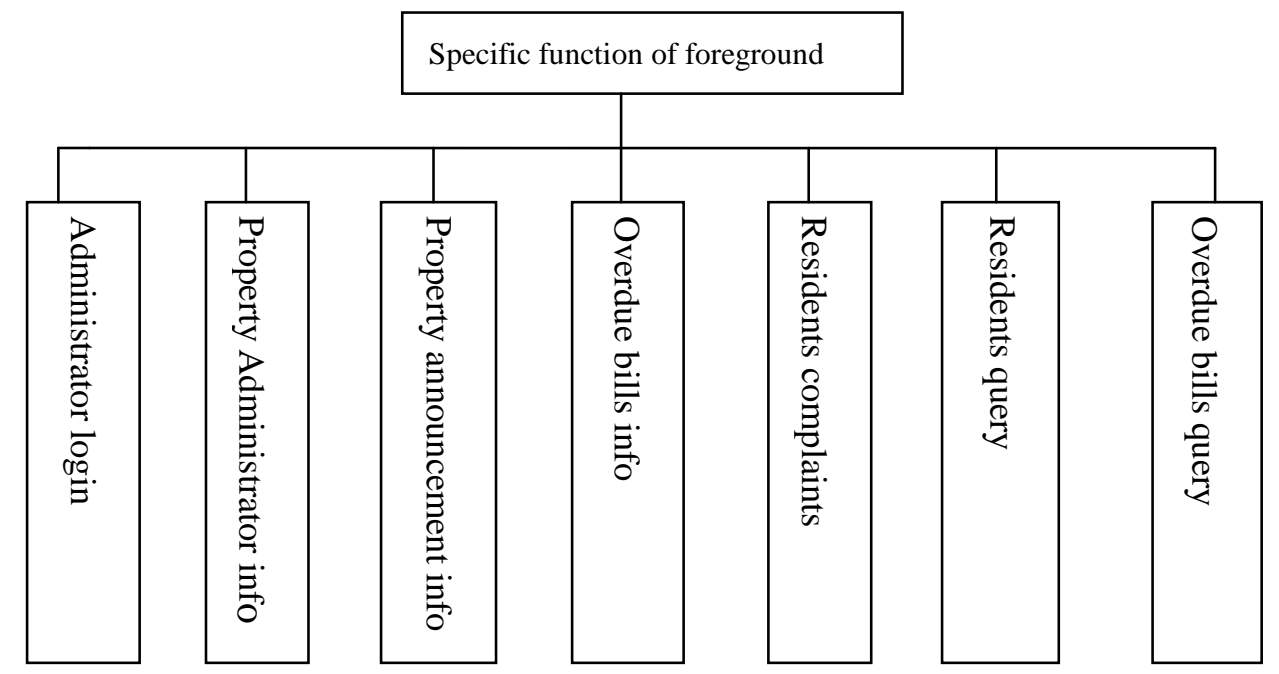

Fig. 1 specific function of foreground

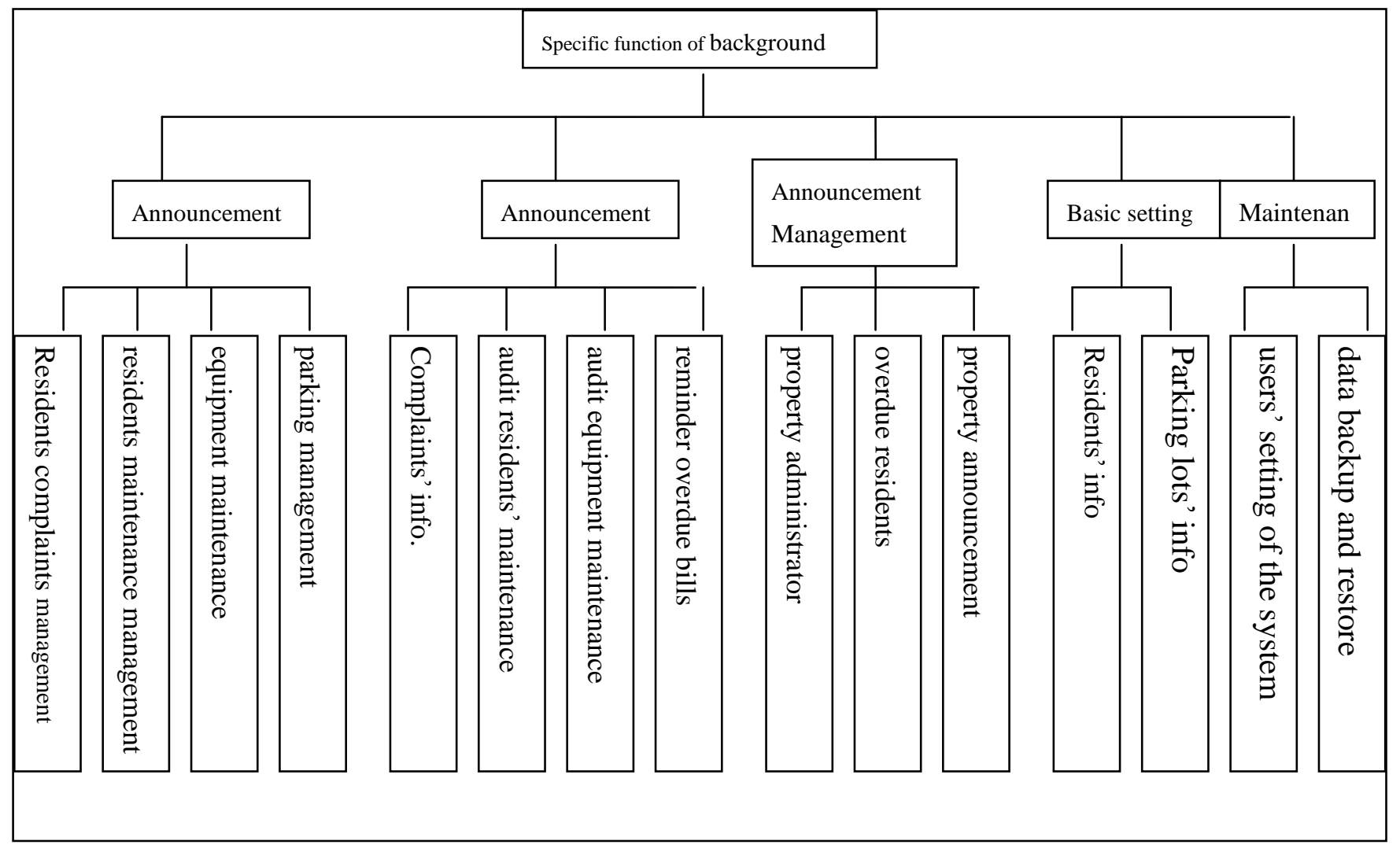

Fig. 2 specific function of background

Rules for system design reference

(1) Event-driven coding; realize the function of organization system through objects (controls can be used in special cases), which is encoded by the background database encoding and the foreground client-side code.

(2) Background database encoding mixed use view and data table, and use rules and limitation to limited data table (such as limit age, gender, etc.). 
(3) Using stored procedures, to relieve the pressure of the foreground coding, so as to improve development and program operating speed.

(4) deleting and modifying each data should be clear hinted (such as the deleted or modified item which is quoted by other programs should not be deleted or modified; adopt the strategy that the items must be removed, or modified should be deleted and modified together with the quoted programs, and write the information into the log in system.)

(5) Prompt the result of the operation in the system.

(6) The date, time used in the system should be subject to date and time of the server. The date adopted by system should be as the unified format of "year-month-day "; with the time of "hour- minute-second"; the date for each statistics and query should be defined as the current season, month and week.

(7) Variates of the system adopts clear definition and written comments; and required the first character of the code should be capitalized, with the length of 16 bits (including letters).

(8) According to the input requirements to establish the input limits (length, type). If involves the uniqueness problem, the data should be checked before leaving focus.

(9) Unified interface style, clear and easy operation, detailed hint of the necessary message, and unified specification of position, size, and color of the space in the interface.

Rules for database coding design reference

Code design is the premise condition for development of database system condition, as well as an important content of the system. Coding refers to the corresponding number, symbol, mark to the original name. It is the key for information exchange, processing, transmission and realizing information resources sharing. Coding is also used to processing method of specified data, the difference between the distinguish data type and specify the content of the computer processing, etc.

The internal information coding of the system adopts the unified coding way, this part will introduce naming code rules of complaint documents, maintenance documents, and equipment maintenance documents:

(1) Number complaint document

Complaint receipt number is current date of the system, the Chinese spell code of "complaint" and the combination of the five figures' code, for example, 2008-06-03 TS10001.

(2) Number maintenance document

Maintenance receipt number is current date of the system, the Chinese spell code of "residents repair service" and the combination of the five figures' code, for example, 2008-06-03ZHBX10001

(3) Number receipt of equipment maintenance document

Equipment maintenance receipt number is current date of the system, the Chinese spell code of "equipment maintenance" and the combination of the five figures' code, for example, 2008-06-03SBWX10001

Main code design of the system. The background code of the system code is completed by $\mathrm{c} \#$, which is mainly about the database operation. The following is partial introduction of the main code.

Public class design.

Public class writing can reduce duplicate code, which is beneficial to code maintenance. Two public class files are created in the system; iDataBase.cs (operation class in database) and 
BaseClass. cs (basic function module class). DataBase.cs is mainly used to access the SQL DataBase, and BaseClass. cs is mainly used for logic function of processing business, which is the form to realize function and business function of database operation. The business function is shown as Fig. 2

The main functions of database operations are: open data connection, close the database connection, release database connections resources, converting parameters and transformed into sqlParameter, executive parameter command text, and add the command text to the sqlDataAdapter; add the command text to a sqlCommand.

The login operation:

The core idea of login is that check the correct password through querying whether the inputted password is in the database, which is simple and understandable.

Database backup and recovery:

Database backup and restore function is achieved mainly by using database operation statements, which is simple.

Examples for function module code design:

In this function module, residents complain information handling will be introduced. The realized functions in this module are complaint information details, check, handling, delete, and other functions.

\section{System implementation}

Code for the related function modules. After finishing main code design of the system, enter the specific coding phase. The completion of the code in this system is realized by utility code implementation and specific code in main module of database design and implementation. In the code, program introduction has been added, which lead to a better understand the method of code realization. The code of this system mainly around the HTML and c \#, public class in the whole system is presented to avoid reuse or writing.

The safety of the system. This system adopted two kinds of methods to enhance system security:

(1) Users' permission is classed according to the functions. Users of different permissions login from the different entrance, and imported to different operation interface to prevent unauthorized operation.

(2) The system is designed functions of data backup and recovery preventing damage of data due to power failure or network virus.

Function module design of the system. After the early stage of the project plan and the later specific code design, this system mainly realized the following function modules: login module and system with the main modules of complaint management, residents service management, feedback information handling, property maintenance, residents parking management, cost management, cost reminder management. The specific function of each module is introduced as follows:

the main function and interface design of foreground in the system

The foreground management of the system mainly includes: the administrator login, information of property management personnel, important notice, notices of overdue bills users, complaints residents, require and query for overdue bills. 
Administrator login is mainly used for security check in background login. In order to prevent users from using robots automatically login, register, chat, the authentication code technology is adopted. The user must through legal login name, password and verification code enter the background of the system.

2) The main function and interface design of foreground in the system

In this design of the property management system, the reception function of the background is than that of foreground, that is to say, administrator privileges is the main access to the system. Although the function is complex, the page is simple and lively, which can make the computer operator with low level of computer skill easily get involved.

Backup and recovery of the system; In the process of operating software system, the data may lose because of the error or virus and etc, especially in business software, once the data is missing, consequence is unimaginable. So the data backup and recovery is an indispensable part of the system.

Function modules of the system user settings used the technology of adding edition and displaying information on the same page, which are mainly database operations of completing add and delete. The design of page is simple; first add a Table control in a new web form which is used for page layout. Then add two TextBox controls which are used to input the users' name and password. Then add a Button control is used to save the input information. Finally add a GridView space used to display all the users' information in the system. The running effect is shown as Fig. 1.

Parking lots management consists of three functional modules: parking lots management function module. The main function is to add and delete the detailed information of the parking space. And display the existed parking information below and here used the GridView control. Parking lots editing function module mainly bases on numbering vehicles and notes the vehicle model for future management. Parking space add function module mainly to add a parking space number and note parking space information.

Users' registration for overdue bill; this function module is also an important business in this system, because application of this system can provide convenience for residents to view their costs condition of water, electricity and gas, and can greatly improve the work efficiency of property management company. This page aims at administrator's permission, which is mainly of adding function for residents with overdue bills. The design is concise and simple. Running effect is as shown in Fig. 2.

\section{Conclusions}

Property management system has larger market prospects, which makes the previous manual management clumsy. The combination of the actual management of community and information management will be inevitable. Property management information system is according to the actual situation of community, after investigation and design for the realization of information management system of community. After the process of requirement analysis, database design and function modules design of the system, the final design of the system includes the following features:

1) This system is of friendly interface, convenient data entry, flexible query and statistics, intuitive statistics' results, nice visibility and convenient for users. 
(2) With complaints module in this system, communication between residents and administrators become smoothly, and greatly provides convenience of meeting residents' demands. The module is the characteristics and advantages of this system.

(3) The cost management module is the emphasis and difficulty in the system, which is of complicated logical relationship. The design of the system basically meets the requirements of daily residential property cost management.

(4) The application of permission management mechanism based on role and verification code, makes administrator can easily define various kinds of roles and permissions also prevent malicious landing and guarantee the security of system access.

(5) Flexible query and statistical function meet the actual needs of users.

Certainly, this system remains many shortcomings. It just covers some basic features of the residential property management. To make this system business available, a detailed secondary development is expected to complete the functions.

\section{Acknowledgements}

This work was financially supported by project of Technology Department of Jiangxi Province [No 20143BBM26048] and the project of Technology Department of Jiangxi Province [No 2013BBE50051] also gives us lots of help.

\section{References}

[1] Zhang, Y. ASP.NET Database System Development Manual. Beijing: people's Post and Telecommunication Publishing Press, 2007

[2] FeiSi Science and Technology Product R\&D Center. ASP.NET Application Development Guide. Beijing: Electronic Industry Press, 2002

[3] Wang, S. Principles of Database System Tutorial. Beijing: Tsinghua University Press, 2002

[4] Chen, X. Actual Use of ASP.NET and Web Development Programming. Beijing: Tsinghua University Press, 2004

[5] Ollie Cornes \& Chris Goode Guide Introduction of ASP.NET, Tsinghua University Press, 2002

[6]Dong,M. ASP.NET Dynamic Web Page Design, Beijing: Tsinghua University Press, 2001

[7] Richard Anderson \& Brian Francis ASP.NET Advanced Programming. Beijing: Tsinghua University Press, 2002

[8] Greg Buczek. ASP.NET Theology and Skill .Beijing: Mechanical Industry Press, 2003

[9] Tang,D. C \# Programming Tutorial. Beijing: Northern Jiaotong University Press, 2003.

[10] Chen, Q. ASP.NET Application Design. Beijing: China Water Conservancy and Hydropower Press, 2004

[11]Zhou, J. ASP.NET Development Technology. Beijing: People's Post and Telecommunication Publishing Press, 2005 